\title{
La oralidad como estrategia de acercamiento al lector en la columna periodística de Antonio Burgos
}

\author{
Orality as a Strategy to Make Antonio Burgos' \\ Newspaper Column Approachable to Readers
}

\author{
Marta León-Castro \\ Universidad de Sevilla \\ martalcg@gmail.com
}

\section{Resumen}

Tradicionalmente se han establecido fronteras más o menos tajantes para delimitar los ámbitos de oralidad y escritura, con una mayor atención y valoración de los rasgos y las estructuras de esta última. Así, muchos hablantes tienen una visión simplista y reducida al ámbito léxico de lo que implica la oralidad. Sin embargo, las columnas periodísticas, donde a menudo sus autores se alejan de fórmulas y expresiones prototípicas del periodismo para crear un estilo propio y reconocible por sus lectores, son un valioso material para estudiar muchos de los rasgos de la gramática de lo oral que se emplean cada día con gran eficacia en soportes escritos. El objetivo de esta comunicación es analizar los usos orales como estrategias de acercamiento al lector en el periodismo escrito a través de las columnas del periodista sevillano Antonio Burgos.

Palabras Clave: oralidad y escritura, columna periodística, Antonio Burgos, estrategias comunicativas, español coloquial

\section{Abstract}

Categorical boundaries have been traditionally established to delimit the domains of orality and writing, in which the last one has received more evaluation and attention with respect to its characteristics and structures. Thus, many people have a simplistic view regarding the lexical domain as it pertains to orality. However, for the study of the grammatical features of oral language which are efficiently used every day in written sources, journalistic columns prove to be valuable material. In such sources, the authors often avoid typical journalistic formulas and expressions in order to create an individual style, which can easily be recognized by readers. The aim of this work is to analyze the use of oral language as a strategy for approaching readers based on the written columns of Sevillian journalist Antonio Burgos.

KEYworDS: orality and writing, journalism, column, communicative strategies, Antonio Burgos, colloquial Spanish 


\section{Introducción}

La realidad discursiva pone de manifiesto multitud de modalidades de uso que rompen con la tradicional oposición oral/ escrito: unas que, pese a difundirse a través de un canal oral, gozan de rasgos propios de lo escrito y otras que poseen características de lo oral, aunque se trate de un soporte gráfico.

Así pues, si tomamos como referencia el soporte escrito, "textos periodísticos y literarios actuales imitan en algún aspecto el registro coloquial con el fin de enriquecer expresivamente el mensaje, la narración, los diálogos" (Briz, 1998: 20).

El objetivo de este trabajo es, en primer lugar, analizar en qué medida la columna periodística resulta permeable a los fenómenos que tienden a considerarse propios de la oralidad en el español actual a partir de un estudio de caso: las columnas del periodista sevillano Antonio Burgos, quien publica diariamente, bajo la rúbrica de "El Recuadro", en el diario de ámbito nacional $A B C .{ }^{1}$ En segundo lugar, nos planteamos realizar un estudio analítico (cuantitativo para determinados aspectos) de sus columnas para detallar qué recursos resultan particularmente productivos en este autor como estrategias discursivas de acercamiento a sus lectores.

Para ello se ha creado un corpus compuesto por 88 de sus columnas publicadas entre los meses de enero y marzo de 2018; se ha prestado atención de entre los muchos rasgos de la oralidad que son frecuentes en este tipo de escritos a los que se vinculan directamente con el lector, es decir, aquellos que configu-

\footnotetext{
${ }^{1}$ Asimismo, sus columnas pueden leerse en su página web El Redcuadro (disponible en $<$ http://www.antonioburgos.com/abc/welcome.html $>$ ), donde también las publica a diario.
} 
ran estrategias relacionadas con el tú-receptor para estrechar sus relaciones de empatía, solidaridad y complicidad.

\section{La oralidad y la escritura en la columna periodística}

El estudio de la oralidad ha tenido siempre un papel secundario entre los investigadores en comparación con el de la escritura, considerado el modelo de prestigio. "En la tradición filológica occidental la lengua ha sido identificada con la escritura" (Mancera, 2009: 22) y se han opuesto de la siguiente manera: "lengua hablada espontánea, eventualmente pintoresca, pero de seguro llena de errores; lengua escrita refinada, que atestigua (sobre todo gracias a la ortografía) la gramática de la lengua" (BlancheBenveniste, 1998: 29).

Hasta finales del siglo xix no empieza a reivindicarse la preponderancia de la oralidad, especialmente con la figura de Saussure. Deja de considerarse como una mera variante deteriorada de la escritura y comienza su estudio científico como manifestación distinta, que no peor, a la escrita.

Otra creencia tradicionalmente asentada ha sido el carácter dicotómico de la oposición oralidad-escritura, en la que se toma como criterio diferencial el soporte a través del cual se transmite el mensaje (canal fónico-acústico o gráfico-visual, respectivamente). Así pues, la oralidad, que se desvanece instantáneamente, emplea signos auditivo-vocálicos y la escritura es un sistema de transcripción del anterior mediante signos gráficos que sí resulta perdurable.

No obstante, la relación entre oralidad y escrituridad o escrituralidad no se corresponde estrictamente con una transcripción gráfica de la vocalidad, sino que, "muy al contrario, el paso de la vocalidad a la escritura modifica las condiciones en que se produce la comunicación" (Bustos, 1998: 102).

En diversos trabajos desde 1985 de Koch y Oesterreicher se plantea la diferencia 'hablado/escrito' que habría que añadir a la ya compleja variación interna de la lengua, que Coseriu (1981) definió a partir de las dimensiones diatópica, diatrática y diafásica. Según estos autores, clasificar una determinada modalidad 
de uso dentro de lo oral o lo escrito sobrepasa los límites del soporte físico (canal) por el que se transmite el mensaje. Debe situarse en realidad en un continuum gradual delimitado por dos polos extremos: 'inmediatez' y 'distancia comunicativa'.

Por tanto, ha de tenerse en cuenta un segundo criterio de análisis, el soporte concepcional empleado; esto es, los modos o realizaciones de lo oral y de lo escrito. El planteamiento multidimensional de Koch y Oesterreicher (1985) supera la creencia tradicional de que lo concepcional sea identificado con lo medial, de manera que los modelos de la inmediatez no necesariamente tienen que recurrir a un soporte fónico.

Así pues, combinando ambos criterios, soporte concepcional y físico, se distinguen cuatro posibilidades ideales: la conversación coloquial se sitúa en el extremo de la oralidad y la inmediatez comunicativa (oral-oral) y en el otro extremo podríamos encontrar ejemplos como un documento jurídico (escrito-escrito). Otros tipos textuales, sin embargo, se encuentran en punto más intermedios, como las publicaciones de las redes sociales, en las que suele hacerse uso de un registro informal (oral-escrito) o la conferencia, donde, pese a la oralidad, existe un alto grado de planificación (escrito-oral).

Si nos centramos en el ámbito del periodismo escrito, la columna es una tradición discursiva que hemos de clasificar cercana a lo oral-escrito; si bien es cierto que el registro (+ coloquial) puede manifestarse tanto en lo oral (fónico) como en lo escrito (gráfico), en este caso en realidad no podemos considerar que haya una concepción oral, transmitida a través de un medio escrito, sino una concepción escrita, en la que los rasgos del español oral se usan como estrategia discursiva (y persuasiva) de acercamiento al lector, ya que "no hay inmediatez en el tiempo y en el espacio, no hay conocimiento mutuo, la comunicación es asimétrica y monolocutiva" (Porroche, 2012: 235).

La columna, aunque con un + (mayor) grado de planificación y formalidad, trata de aproximarse a algunos de los parámetros situacionales que definen, según Briz (1998: 27) la modalidad de uso coloquial oral: + relación de proximidad, + saber compartido, + cotidianeidad y + finalidad interpersonal. 
Sin embargo, solo se realiza parcialmente, de manera que "aunque el columnista lleva a cabo continuamente un trasvase a la escritura de estrategias prototípicas de la oralidad concepcional, ha de establecer una especie de filtro adaptador que facilite la eliminación de todo lo que entorpecería la columna" (Mancera, 2008: 470).

El DLE (2014) define la columna, por un lado, como género periodístico y, por otro como "artículo de un colaborador o redactor que aparece de forma regular y frecuente en un espacio fijo" dentro de una publicación periódica. Puede clasificarse en dos grandes grupos: las columnas analíticas y las columnas personales $^{2}$ (Casals, 2000: 38).

Para Casals la columna personal es "un artículo de opinión firmado por un autor de presumible valía literaria - aunque a veces irrite la presunción por fuera de lugar-, con seguidores ideológicos o simplemente admiradores de su estilo, y que aparece publicado en el mismo diario con periodicidad y en el mismo espacio reconocible" (2000: 43).

Resulta tan importante el fondo como la forma, por lo que su libertad temática y formal permite al periodista "mostrar una manera de ser y de comportarse ante los acontecimientos, así como una determinada concepción del mundo que le rodea" y, que ello, sumado a "la intimidad, la confidencia, la confesión de lo que le acontece al propio autor" sean clave para que el interlocutor quede especialmente atraído (Mancera, 2008: 477).

El columnista se propone crear lazos de complicidad con sus lectores, convertirlos en seguidores asiduos de sus escritos diarios y para ello emplea estrategias de diversa índole. Podemos considerar una de ellas la tendencia actual a que aparezcan elementos como su foto e incluso un correo electrónico o sus redes sociales para favorecer la comunicación entre ambas partes. Asimismo, la presencia de los rasgos de oralidad se explica en gran medida por este deseo del periodista, de manera que el

\footnotetext{
${ }^{2}$ A este grupo pertenecen las columnas del periodista Antonio Burgos, objeto de estudio de este trabajo.
} 
tono familiar e intimista parece erigirse en fundamento de este tipo de escritos.

Sin embargo, se evidencia una explotación diferente en el habla y en este tipo de columnas de lo que en apariencia son los mismos recursos, dada las condiciones de espontaneidad y planificación en que se producen una modalidad de uso y otra respectivamente.

En definitiva, si bien es cierto que las condiciones comunicativas en las que se produce el coloquio prototípico y la columna periodística difieren enormemente, también lo es que el periodista se vale de una serie de recursos propios de la inmediatez comunicativa para "otorgar a su discurso cierta apariencia de espontaneidad que lo asemeje a la conversación, tratando de fingir así una cercanía y una connivencia con el lector que lo atraigan" hacia su punto de vista (Mancera, 2009: 66).

\section{Análisis del corpus}

En el estudio de las columnas periodísticas de Antonio Burgos se han tenido en cuenta como criterios de análisis aquellos rasgos de la oralidad que pueden considerarse estrategias discursivas ${ }^{3}$ que consideramos relacionadas con el papel del receptor. Por tanto, hemos descartado otros que, pese a que son habituales en este tipo de textos, ya han sido ampliamente estudiados ${ }^{4}$ y/o no responden a los objetivos específicos que aquí nos planteamos. ${ }^{5}$

\footnotetext{
${ }^{3}$ Pese a que en Análisis del discurso se observan diversos empleos para este término y también diversas definiciones según la corriente de investigación (Charaudeau y Maingueneau, 2005: 245), entendemos por estrategia discursiva el plan que un hablante lleva a cabo con el fin de obtener o, al menos, tratar de obtener una comunicación efectiva (no siempre el éxito de la comunicación está asegurado, pues puede que no se reconozca la intención o no se comportan los presupuestos involucrados). Su conformación depende de la combinación de recursos gramaticales y pragmáticos (Menéndez, 2000: 923-930).

${ }^{4}$ Véase Narbona (1989), Briz (1998), Mancera (2009), etc.

${ }^{5}$ Con respecto al léxico, planteaba ya Narbona (1994: 725) que tradicionalmente ha gozado de un interés preferente en los estudios de oralidad, así como "la fraseología fijada y los giros estereotipados", lo cual "es observable también en los escasos tratados que se centran en el español coloquial en general”. Hoy muchos hablantes
} 
Hay fenómenos habituales que, pese a que pueden considerarse recursos persuasivos y de acercamiento al lector, están más orientados al yo-hablante, de manera que priman otras intenciones comunicativas tales como mostrar la presencia del propio periodista en su discurso y su afectividad ante lo dicho, por lo que también han sido descartados para su análisis en este trabajo. ${ }^{6}$

Si bien la emotividad o subjetividad es una característica esencial de la columna de opinión, también lo es la interactividad; el columnista quiere acercarse a su público y para ello trata de integrarlo y hacerlo partícipe mediante diversos mecanismos. Así pues, nos hemos centrado en las siguientes cuestiones relacionadas con la figura del tú-receptor:
a) deixis y fórmulas de tratamiento;
b) vocativos y marcadores discursivos;
c) estilo directo y modalidad interrogativa.

Ha de tenerse en cuenta "cómo la figura del receptor está «virtualmente» presente en la mente del hablante" y, por tanto, cómo se manifiesta esto en la organización del texto y en los mecanismos que se eligen (Fuentes, 2000: 169).

\subsection{Deixis y fórmulas de tratamiento}

Una de las más destacadas es la deixis, que relaciona el discurso con la situación comunicativa en que se produce y proyecta sobre este "la inevitable egocentricidad del sujeto hablante, que es quien vive y comparte la situación de interacción comunicativa y quien tiene que cifrarla o codificarla verbalmente para su interlocutor" (Vigara, 2000: 95).

\footnotetext{
siguen percibiendo la oralidad presente en un texto escrito tan solo por las muestras del léxico empleado; es por todo ello por lo que descartamos un estudio desde este punto de vista.

${ }^{6}$ Nos referimos a recursos de personificación y despersonificación, parentéticos, interjecciones o determinados marcadores discursivos que si bien acercan enormemente el texto a la concepción oral, focalizan la atención en el propio periodista.
} 
En el discurso periodístico "suele darse un elevado grado de separación local y temporal entre el momento de producción y el de recepción del discurso. Esto lo distingue de la situación de encuentro cara a cara propia del coloquio" (Mancera, 2009: 65) y provoca diferencias en la deixis (aquí, allí, etc.), ya que a menudo el referente del discurso es el propio hablante. Sin embargo, la particularidad en las columnas de Burgos es que tiende a resolver esa distancia saliendo del plano de la enunciación para adoptar el punto de vista del lector.

Para las referencias temporales, el periodista sacrifica la presencia de su propio ahora y lo sustituye por el del receptor, de manera que se sitúa en el plano de la recepción para emplear los deícticos de forma que sus referentes no susciten ambigüedad o confusión a sus lectores:

(1) Esta tarde, a las ocho y media, por ejemplo, se inaugura en el Mercantil algo tradicional cofradiero que antaño se celebraba en el Ayuntamiento, en el Salón Colón: la llamada "Exposición de Estrenos". Allí llevaban las cofradías todo lo nuevo que salido de los talleres de bordadores, talladores, doradores y orfebres iban a estrenar en la inminente Semana Santa ("Ya de estrenos", 23/02/18)

(2) Tal ocurrirá mañana en el Congreso de los Diputados, donde PSOE, Podemos, PNV “et alii", excepto PP y Ciudadanos, pedirán la derogación de la prisión permanente no revisable [...]. Si en España hubiera vergüenza, que cada día lo dudo más profundamente, hoy, como se echaron a la calle las mujeres para pedir su igualdad frente a los hombres o los jubilados para exigir pensiones sin pérdida de poder adquisitivo, nos tendríamos que manifestar ("Clamor no revisable", 14/03/18)

En el ejemplo (1), se refiere a una inauguración que tiene lugar en la tarde del día 23, fecha en que se publica el artículo y se prevé que sea leído. En (2), habla de una convocatoria de los diputados al Congreso prevista para el día posterior a la publicación y probable recepción de la columna, de ahí el empleo del adverbio demostrativo mañana. 
E incluso esta tendencia a situarse en la esfera del receptor provoca que modifique otros elementos de la oración; como en el ejemplo (3), en el que emplea el pretérito perfecto para una acción que, en el momento de la enunciación (todavía sábado) sería futura:

(3) Sé que son obviedades. Perdonen que les haya hecho perder el domingo con ellas, pero es que al ver cómo aquí las anormalidades se consideran ya normales me hierve la sangre. Española, por supuesto ("Anormalidades que pasan por normales", 4/03/18)

El papel destacado del lector en las columnas de Burgos también se pone de manifiesto muy claramente gracias al empleo continuado de formas de tratamiento con las que se dirige a él. De entre las que ofrece el sistema pronominal español, el periodista selecciona la que tradicionalmente se ha considerado la forma de respeto, ya que "el trato de usted dirigido a los desconocidos adultos sigue siendo, con escasa excepciones, la norma común en el español general contemporáneo" (RAE, 2009: 1252).

Utiliza siempre las formas de respeto, tanto cuando se dirige a un lector ideal ficticio como al grupo de todos ellos:

(4) Entren a ese patio del antiguo convento de San Acacio, escuchen las fichas de dominó sobre el mármol, o entren en el silencio de la biblioteca... o en el butacazo postprandial en la gutaperecha verde ("Ya de estrenos", 23/02/18)

(5) Conclusión: beba usted agua del grifo, hombre, que es la mejor. No solamente en su casa de usted, como hacemos todos, sino en público, en los restaurantes. ¡Atrévase, hombre! ("Beba agua del grifo", $2 / 03 / 18)^{7}$

(6) Les animo, pues, a que visiten este museíllo sobre la importancia de Tablada en los vuelos de las "alas gloriosas de España", para que como sevillanos sientan, como cantan los aviadores en su

\footnotetext{
${ }^{7}$ Sirvan los ejemplos expuestos para ilustrar la frecuencia con que se emplean formas imperativas para aconsejar al lector, invitarlo a salir de la columna y conocer lo narrado por sí mismo.
} 
himno pemaniano, "la gloria infinita de ser español" ("Histórica Tablada", 12/03/18)

Llama la atención que el lector, situado en una posición superior y merecedor de todos los respetos, sí tutea al periodista:

(7) Como las manifestaciones, protestas y salvajes algaradas tras el bulo lanzado por Carmena y los suyos sobre el nigeriano muerto de un infarto ha tenido mucho de echarle al PP encima el problema de la inmigración.

- Veo que defiendes mucho al PP... (“Todo es bueno para el convento", 21/03/18)

No obstante, el deseo de formalidad por parte de Burgos no impide el cambio de deíctico a la forma familiar tú cuando expresa opiniones o vivencias generales. A este respecto, Fernández Ramírez (1986: 48) afirma que la tendencia es a elegir tú o usted con valor genérico en función del tratamiento que se le dé al oyente, aunque reconoce que a veces se emplea tú cuando se trata al receptor de usted (nunca al revés).

DeMello (2000: 364-366) también defiende que el uso de usted impersonal se documenta casi exclusivamente entre hablantes que se tratan de usted. No obstante, reconoce cierto empleo de usted impersonal por parte de hablantes que se tutean y de tú impersonal entre personas que se tratan de usted.

Es esta última posibilidad la que coincide con la elección del columnista: prefiere utilizar mecanismos diferenciados para dirigirse al interlocutor y establecer generalizaciones. En el primer caso, la elección de usted obedece a una cuestión de máximo respeto para con sus lectores, y en el segundo, la de tú, responde, por un lado, al deseo de incluir no solo a ellos sino a sí mismo (y a todo el mundo) y, por otro, a una tendencia actual en el mundo hispánico, pues el mayor grado de tuteo en la esfera pública en los últimos tiempos ha propiciado que se generalice más con la forma tú que con la de tratamiento usted (Kluge, 2010:115). 
La interpretación referencial de usted o ustedes y la indefinida de tú son constantes, ${ }^{8}$ de modo que no existe ambigüedad alguna, lo que posibilita que aparezcan en el mismo contexto; las referencias directas a los lectores se combinan con un tú generalizador:

(8) Así que ándense con precaución en estos días, porque Sevilla está que, si te descuidas, te dan un premio de Semana Santa (“¡Peligro, premios!", 15/03/18)

(9) Miren: estamos acabando enero, el de la Cuesta tan famosa como la del Bacalao, y aún no han aparecido, como otras veces, los baruntos de los días del gozo. Y mira que este año cae temprano la Semana Santa ("Esa luz que tarda", 30/03/18)

El empleo de tú como mecanismo de indefinición referencial es toda una estrategia de persuasión; su eficacia reside en acercar al interlocutor al discurso: se busca su apoyo para que se implique en lo dicho. De este modo, sirve para personalizar la situación y crear afiliación (León-Castro, 2014: 48).

\subsection{Vocativos y marcadores}

Con respecto a los vocativos, se trata de un recurso habitual en el corpus, pero tan solo en una ocasión lo encontramos con referencia al lector ("Pues visitan, querido lector, ay, la que hay" (“Sevilla Global”, 29/01/18)). A pesar de la insistencia del autor por mantener la atención de sus receptores, se vale de otros muchos mecanismos y reserva este para dirigirse a personas determinadas: políticos, empresarios y miembros, en definitiva, de la esfera pública a los que suele recriminar su actuación en algún asunto:

(10) Pues nada, doña Susana Díaz, si para ganarse las habichuelas y

\footnotetext{
${ }^{8}$ En un estudio del habla urbana de Sevilla (sociolecto bajo; esto es, entre hablantes con un nivel de instrucción mínimo) observamos la misma preferencia por el empleo de la forma familiar tú frente a usted como mecanismo de indefinición referencial con cualquiera de sus interpretaciones semánticas (León-Castro, 2015).
} 
el pan de los niños y pagar la hipoteca del piso hay que hacer meditación budista, se hace ("Mi meditación (nada budista)", $11 / 01 / 18)$

(11) Por cierto, señor alcalde: a ver si tira usted de los fondos del Alcázar o pone una tasa a cada entrada, para arreglar los conventos de clausura que se nos están cayendo, como Madre de Dios, San Leandro o Santa Inés y tantos otros ("Las aceras que perdimos", 19/01/18)

(12) Han hecho otro hotel de lujo en las que fueron Escuelas Francesas de la calle Abades, cargándose por cierto completamente el histórico edificio, queridos amigos de Adepa, sin que Urbanismo abriera la boca ("La burbuja turística", 3/02/18)

No obstante, hemos registrado algunos ejemplos que muestran una intención diferente en el uso del vocativo; resultan un guiño en la columna para homenajear a un ser querido por el periodista y/o buscar su apoyo. La referencia a estas personas concretas, también influyentes en la sociedad sevillana, refuerzan la argumentación de Burgos y evidencian su posición social y sus buenas relaciones: “¿verdad, Antonio Dubé de Luque?"” (“Sevilla, una emoción”, 9/02/18), “¿o me equivoco, querido arzobispo don Juan José Asenjo?” ("La fe y el arco”, 13/03/18), “¿no, profesor Giráldez?” (“Cruz de Guía”, 19/03/18).

En la mayoría de casos aparecen tras apéndices comprobativos como los anteriores (¿no?, ¿verdad?) que buscan la cooperación y la complicidad con la persona aludida e incluso con el propio lector. Forman parte de los marcadores del discurso, los cuales presentan usos discursivos, enfatizadores y valores expresivos pertinentes para el estudio que nos ocupa.

Nos hemos centrado en los marcadores conversacionales, definidos como fenómenos de construcción discursiva, pues "sirven de apoyo discursivo al hablante" (Carbonero, 1999: $216)^{10} \mathrm{y}$, en este caso, refuerzan la función de contacto con el interlocutor. Siguiendo para su análisis la clasificación de Mar-

\footnotetext{
${ }^{9}$ Escultor e imaginero, especializado en tallas religiosas.

${ }^{10}$ Los denomina muletillas (vamos, ¿no?, claro, etc.).
} 
tín Zorraquino y Portolés (1999), los que mayor rendimiento tienen en las columnas de Burgos son los siguientes:

\begin{tabular}{|c|c|c|c|}
\hline $\begin{array}{c}\text { Enfocadores de la } \\
\text { alteridad }\end{array}$ & $\begin{array}{c}\text { Marcadores de la } \\
\text { mod. epistémica }\end{array}$ & $\begin{array}{c}\text { Marcadores } \\
\text { de la mod. } \\
\text { deóntica }\end{array}$ & $\begin{array}{c}\text { Metadiscursivos } \\
\text { coversacionales }\end{array}$ \\
\hline $\begin{array}{c}\text {-Apéndices } \\
\text { comprobativos: }\end{array}$ & $\begin{array}{c}\text {-Marcadores de } \\
\text { evidencia: } \\
\text { claro (que) (10) }\end{array}$ & -Bueno (2) & $\begin{array}{c}\text {-Bueno (pues) } \\
\text { ¿no?(5) }\end{array}$ \\
$\begin{array}{c}\text { ¿verdad? (2) } \\
\text {-Hombre (7) } \\
\text { naturalmente (10) } \\
\text { evidentemente (4) }\end{array}$ & & - Sí (11) \\
-Hijo (y variantes) (4) & & & \\
-Vamos (14) & & & \\
\hline
\end{tabular}

Cuadro 1. Marcadores conversacionales

1. Enfocadores de la alteridad, que apuntan al oyente y son los que mayor presencia tienen en el corpus analizado; se incluyen en este grupo los apéndices comprobativos y otros marcadores como hombre, que otorga un tono amistoso al discurso, pues "tiñe las relaciones entre los interlocutores de cierta familiaridad o complicidad” (Martín Zorraquino y Portolés, 1999: 4173), incluso, como ocurre en las columnas de Burgos, cuando no se da el tuteo:

(13) Si usted en su casa bebe agua del grifo, no le dé corte ninguno pedirla en el restaurante, hombre. Sobre todo cuando nos consta que estamos pidiendo la mejor agua de España. Esa: la de Emasesa. Como es Lunes de Carnaval, yo tendría hoy que escribir... ("Beba agua del grifo", 2/03/18)

Podría pensarse que el apelativo hijo y sus variantes tienen ese mismo tono cariñoso. Sin embargo, no lo emplea en ningún caso para reforzar la buena relación con el interlocutor, sino con referencia a personas concretas para atenuar la crítica o el reproche que les dirige:

(14) A la selección femenina también parece que le repele la palabra "España”, y en un anuncio oficial previo al Campeonato Mundial

\footnotetext{
${ }^{11}$ Entre paréntesis recogemos el número de casos registrados en el corpus.
} 
de Alemania, proclamaron: "Nuestro nombre es Guerreras". No, hijas, no; no, señores autotitulados Hispanos: vuestro nombre es España. Que es la palabra que tampoco quieren nombrar los que hablan de La Roja ("Los Hispanos", 1/02/18)

(15) Habían anunciado la encerrona en Barcelona, que rima. Que al Rey le iban a montar la del tigre. Tan torpes son. Esas cosas se preparan y se hacen, pero chitón, hijos, es elemental, querido Watson, en cualquier manual de táctica y estrategia ("Rey en primera línea", 28/02/18)

Vamos es el enfocador de la alteridad más frecuente en nuestro corpus; aunque puede adquirir valores diversos, siempre fortalece las relaciones con el interlocutor, ya que lo implica en lo dicho a través de la marca de primera persona del plural de la partícula:

(16) Hay otro pretexto precioso: un cursillo sobre "Gestión de los Programas de Fondos Europeos en Andalucía”. Vamos, para aprender a hacer Centros de Interpretación de la Carriola Rociera, Observatorios del Escarabajo Pelotero y esas tonterías en las que se gastan el jurdó europeo la Junta y los Ayuntamientos. ("Mi meditación (nada budista)", 11/01/18)

Se trata de una estrategia de cortesía positiva, puesto que refuerza la imagen del propio hablante: "favorece la comunión, con su propio discurso, de los participantes de la conversación, al incluirlos en la misma esfera enunciativa" (Martín Zorraquino y Portolés, 1999: 4177-4178).

Para Beinhauer, su uso se explica por la necesidad del hablante de estrechar el contacto con el interlocutor cuando se atasca en su discurso; "le hace partícipe, diríamos, de su turbación" (1963: 414).

Mancera lo destaca como un uso habitual por parte de los columnistas: resalta la enunciación, “ajustando lo dicho a la intención del hablante, a la manifestación de su propia subjetividad. Suele emplearse como exclamación de enfado o de protesta, o para incitar a realizar una acción" (2009: 146). Es con la fun- 
ción de precisar un fragmento anterior como lo hemos apreciado en la mayoría de los ejemplos registrados:

(17) Como, bajando de lo sublime a lo más humano, es patrimonio emocional puro, vamos, de lagrimones, ese olor a adobo cuando se pasa por la esquina de Blanco Cerrillo en la calle Velázquez (“Catálogo de repeluco", 6/02/18)

2. Marcadores de modalidad epistémica: se utilizan fundamentalmente en enunciados declarativos y constituyen en sí mismos una aserción. Los que marcan la evidencia indican que lo dicho es algo compartido por la comunidad (Fuentes y Alcaide, 2002: 114), de modo que sirven para apoyar la argumentación del hablante y, con ello, persuadir al receptor.

En concreto, naturalmente y claro son los más recurrentes en las columnas de Burgos según nuestro análisis:

(18) ¡Qué tabarra más grande con el empecinamiento de estos señores pesados, pesados, pesados! Hay que ver la tabarra que están dando a España estos señores independentistas. Tabarra telemática, naturalmente, como pide el más jartible de todos. El que más tabarra y más por saco da (“Tabarra Catalana”, 14/01/18)

(19) La Montero, poniéndose la lengua castellana por montera, por aquello de Montero y Montera, claro, ha anunciado que en un acto de Podemos en el Círculo de Bellas Artes iban a participar "portavoces y portavozas del grupo parlamentario" ("La portacoz", 11/02/18)

La alta rentabilidad de claro en las columnas periodísticas, en general, se debe a que consigue implicar al lector "con la visión personal del propio columnista, reforzando su imagen positiva, y favoreciendo su identificación con él" (Mancera, 2009: 160).

3. Marcadores de modalidad deóntica: de entre ellos destaca el uso de bueno. Si bien no lo hemos encontrado como enfocador de la alteridad, ${ }^{12}$ sí lo hemos registrado en nuestro corpus como mar-

${ }^{12}$ Seguramente se deba a que, con este valor, bueno "se emplea normalmente al 
cador de modalidad deóntica; esto es, como elemento asertivo, reflejando la actitud del hablante conforme a lo dicho anteriormente:

(20) O plastas, voz que también los define muy bien: "Pepe es un tío plasta". Bueno, pues ahora tenemos ya suelto, en todo lo suyo, al pesado de Semana Santa, como más tarde habremos de tener al de Feria ("De este año no pasa”, 17/03/18)

4. Metadiscursivos conversacionales: el hablante recurre a ellos para organizar su discurso conforme lo formula y lo reformula sobre la marcha. Así como para regular el contacto con su interlocutor. Briz (1998: 201) los llama marcadores metacomunicativos, pues son resultados de las estrategias comunicativas por parte del hablante a la hora de producir y formular sus mensajes.

Hemos de señalar por su recurrencia el marcador sí. No lo encontramos en los contextos prototípicos como marcador metadiscursivo (dado, lógicamente, el carácter monolocutivo de la columna periodística), no obstante, podemos considerar que funciona de esta manera en la medida en que introduce una réplica del propio periodista a un supuesto comentario o pregunta que imagina por parte del lector y que en la mayoría de las ocasiones hay que inferir:

(21) Se habla mucho en política de las "puertas giratorias", de los que salen de un carguete en un partido y les buscan inmediatamente otra mamela, pública o privada. ¿Y las "puertas giratorias" de la Justicia? Sí, eso que siempre se ha dicho, que cuando cogen a un delincuente y lo llevan al juzgado, "entra por una puerta y sale por otra" ("Clamor no revisable”, 14/03/18)

(22) Envidiaba a Pachi Bores y su maravillosa casa de la calle Santa Teresa, casi saliendo ya a la Plaza de Santa Cruz, que no sé si saben fue un invento. Sí, la Plaza de Santa Cruz la inventó don

inicio de una intervención reactiva que implica un cierto desajuste, oposición, disconformidad, desacuerdo, etc. con el interlocutor" (Martín Zorraquino y Portolés, 1999: 4176). Burgos permite que su lector discrepe, pero al revés no: el periodista no se muestra disconforme con él. 
Santiago Montoto cuando fue concejal del Ayuntamiento (“Tiene un tesoro", 24/02/18)

Y finalmente, debido a lo mutifuncional que resulta el empleo de bueno en la oralidad, también aparece como metadiscursivo conversacional en el corpus analizado. Implica una acumulación de información y sirve para continuar la comunicación tras un fragmento lateral respecto a lo anterior (Martín Zorraquino y Portolés, 1999: 4196):

(23) Sacan de vez en cuando colecciones de fotos de un famoso fotógrafo extranjero que vino a la Semana Santa de 1930, por ejemplo. Y sale el amigo del nazareno que pintó Martínez de León, y las pilas de sillas en La Campana, y un amanecer de Viernes Santo con antifaces remangados sobre el macho del capirote y copas de aguardiente en los veladores. Bueno, pues eso mismo, pero de aquí, y sintiendo a Sevilla, fue lo que ha hecho toda su vida Jesús Martín Cartaya ("El hijo del espartero", 13/02/18)

Sobre todo lo utiliza seguido de pues, para volver sobre el tema tras una observación o una pregunta del propio periodista:

(24) ¿Se acuerdan de aquella canción de un programa infantil de la tele, "Un globo, dos globos, tres globos"? Bueno, pues así podríamos calificar, a modo de estrellas de hoteles o de tenedores de restaurantes, la importancia de las fiestas callejeras en Sevilla, civiles o religiosas (“Sevilla Global”, 29/01/18)

\subsection{Estilo directo y modalidad interrogativa}

En cuanto al recurso del estilo directo, aunque la columna se defina como un discurso asimétrico y monolocutivo en el que solo interviene un único hablante, no hemos de olvidar que, como cualquier acto de comunicación, forma parte de una práctica social y "es de carácter interaccional, pues su sentido social se construye gracias al encuentro entre una instancia de emisión y una instancia de recepción" (Mancera, 2009: 56). 
Además, en el caso particular de las columnas de Burgos, la participación del lector en la comunicación se finge continuamente mediante diversos recursos. Así pues, sus reacciones, que el columnista imagina ante sus propios comentarios, son plasmadas en el texto ${ }^{13}$ y tratan de mostrar cierto grado de cooperación ("el papel que el receptor juega en la elaboración de los enunciados") que, en el caso del coloquio, es tan importante (Mancera, 2009: 63):

(25) Agraciadas no eran ciertamente las muchachas, y no se les ocurra acusarme de machista por constatar simplemente un hecho. Es como si me llaman astrónomo por apreciar que el sol suele ponerse al atardecer (“iNekanes a Suiza!”, 25/02/18)

(26) No se rían, que esto es muy serio, que estoy viendo cómo los dueños de los bares que se han tenido que fastidiar en los mejores días de negocio y ventas pueden ver, impotentes, cómo a la puerta se les colocan los manteros subsaharianos y tampoco dejan caminar a la gente, aun cuando no pasen cofradías ("Calle Manteros", 9/03/18)

(27) Siglos en los que, por cierto, no se cogían vacaciones de Semana Santa, sino que, por el contrario, casi se paralizaban las ciudades, se cerraban los cines y teatros y en la radio sólo ponían música sacra o cofradiera, porque se trataba (y se sigue tratando, aunque no lo parezca) de la conmemoración de la Pasión. Sí, ya sé, ya sé que en Málaga, en Zamora, en Valladolid o en mi Sevilla, y sigan poniendo ciudades, sí que se celebra la Semana Santa por el plan antiguo (“Semana Santa 'sin'”, 28/03/18)

Aunque los ejemplos anteriores revelan una situación monologal y monológica, hacen presente al interlocutor. Hay que tener en cuenta, por tanto, "diversos grados de presencia del re-

\footnotetext{
${ }^{13} \mathrm{E}$ incluso provoca que en ocasiones se excuse ante lo que para el autor es una reacción probable en el lector:

La frase de Luis Cernuda en "Ocnos" es bastante conocida. Así que perdonen $s i$, citándola una vez más, la convierto en algo que el poeta odiaba: un tópico sevillanito ("La Fe y el Arco", 13/03/18).
} 
ceptor en los textos" (Fuentes, 2000: 167), que forman un continuum en el que se observan distintas situaciones que van desde un receptor no presente a otro mencionado o incluso activo (Fuentes, 2000: 168).

En otros casos, sin embargo, la presencia del receptor se muestra mucho más activa, pues a menudo aparece la voz de un lector ficticio que interrumpe al periodista al hilo de la narración:

(28) Como es Lunes de Carnaval, yo tendría hoy que escribir... ¿De Cádiz? No, hombre, que no quiero ser jartible ("Miedo me da...", $12 / 02 / 18)$

(29) Dice ese mármol del macareno Arco de la felicidad cernudiana: "El domingo 27 de mayo del año de gracia de 1923 tomó posesión solemne de este Arco de la Macarena la que es Hija del Eterno Padre, Madre del Verbo Divino, Esposa Inmaculada del Espíritu Santo, Amor de los Amores de Sevilla y Esperanza única de los mortales".

$-; O ́ l e !$

No, espere, que el mármol sigue (“La Fe y el Arco”, 13/03/18)

Su participación para cuestionar e incluso replicar al propio Burgos es muy frecuente en sus columnas. De sus comentarios se desprende una imagen del lector muy positiva: inteligente, agudo y atento, al que nada se escapa:

(30) Sí, ya lo sé, no me digan el argumento en contra de mis preguntas y de mi indignación, pues me lo conozco de sobra, de muchos otros años. Ese que dice:

-Pues en Semana Santa también se corta la ciudad entera $y$ nadie protesta.

No, señor mío, no: la ciudad entera no. El centro, y, en el mejor de los casos, la Sevilla intramuros de la antigua cerca (“Maratón ni son", 26/02/18)

(31) - En Sevilla está todo inventado.

Depende. Lo de hoy, lo del Santo Martes, con la Carrera Oficial a contraquerencia o a la suerte contraria, por decirlo en términos taurinos (“Estrenos y simultaneidad", 27/03/18) 
Asimismo, el columnista le transfiere sus propias cualidades; le dota del humor que lo caracteriza a él mismo y que considera uno de sus recursos más eficaces para seducir al lector. Resulta un componente fundamental en sus columnas, pues, como el propio Burgos reconoce, "por muy graves que sean las irredentas cuestiones patrias, el cachondeo nunca debe faltar, pues ya saben: el humor es un arma de destrucción masiva y la mejor defensa" ("El referente", 24/01/18).

Se trata de otro mecanismo de cortesía para empatizar con el interlocutor, pues, a partir de su empleo, este queda retratado como un individuo competente, ingenioso y capaz de vencer al periodista con sus propias armas, como si se tratara de una lucha dialéctica:

(32) Ya saben mi tesis: el habla sevillana, la riquísima habla sevillana, quintaesencia del andaluz, molde del español que pasó a América con el Descubrimiento y Conquista, es un monumento (Bien de Interés Cultural que le llaman ahora), pero no de piedra ni adobe.

- ¿En adobo entonces?

Menos cachondeíto, por favor, que estamos hablando de un asunto tan serio como el habla sevillana, monumento vivo que hay que conservar y mantener ("Elogio de la rebaná", 3/03/18)

(33) Así que, como habrán visto, entre sevillanas y fandangos, no sé con qué Raya quedarme:

-Pues como vamos por Huelva, quédese con la Raya de Portugal y así compramos toallas en Vila Real de Santo Antonio.

Menos cachondeo. Que no sé si quedarme con aquel Raya de "Los Rocieros" con su inseparable Santiago Martín ("El Raya", 27/02/18)

Se pone de manifiesto que respetar y reforzar la imagen positiva del interlocutor tiene un papel fundamental en la comunicación de masas, pues es una técnica de captatio benevolentiae: lo predispone para que adopte una actitud positiva y acepte el mensaje emitido como "digno de ser tomado en consideración. La estrategia en cuestión se denomina "persuasión coactiva»" (Haverkate, 1994: 30). 
Asimismo, aparecen otras voces enunciadoras, "fruto de la elaboración del discurso llevada a cabo por el propio columnista", que, aunque no puedan equipararse al dinamismo y a la interactividad real de los coloquios prototípicos (Mancera, 2009: 63), recrean la oralidad todavía más fielmente que el discurso de Burgos, pues están cargados de elementos que ofrecen mayor sensación de naturalidad y espontaneidad, ${ }^{14}$ pues forman parte de un diálogo real o imaginado:

(34) Tomó el hombre el aparatito y con la tajá se creyó Julio Vera. Y les dijo a los municipales, chispa más o menos:

-Soplar el aparato no lo pienso soplar. Pero verán ustedes qué marcha de la Banda de las Tres Caídas de Triana tan bonita les voy a tocar con él ("Concierto de alcoholímetro", 17/02/18)

(35) El presidente del Parlamento autonómico, Roger Torrent, y posterga "sine die" la sesión, casi como en el anuncio de la gaseosa:

-Ea, pues si al preso preventivo por rebeldía y sedición no lo podemos tener aquí en el Parlamento autonómico para elegirlo fallera mayor de la República Independiente de Cataluña, nos vamos... Nos vamos a pegar el chivatazo a mi primo de Zumosol del Tribunal de Derechos Humanas de Estrasburgo. No hay derecho a que nos obliguen a elegir como presidente a un señor normal, que ni esté en la cárcel por sedición, ni fugado en Waterloo por cobardía, ni nada, ¿habráse visto? (“Todo es simbólico”, 11/03/18)

El registro coloquial se plasma independientemente del nivel sociocultural de los personajes. En los ejemplos (34) y (35) se refiere a un joven camarero y al presidente del Parlamento Catalán respectivamente.

Estas intervenciones, a diferencia de las del lector, no interrumpen el discurso, sino que son discursos referidos que el propio periodista incorpora a la narración y que no necesariamente introduce con un verbum dicendi. En cualquier caso, aportan viveza al relato, credibilidad, y mantienen la atención

\footnotetext{
${ }^{14}$ En ambos ejemplos aparecen rasgos tan característicos de lo oral como el infinitivo pretemático, la alteración del orden prototípico, las oraciones suspendidas o la presencia de la interjección ea.
} 
del receptor. Y tienden a ser discursos humorísticos o irónicos que refuerzan la creencia de que la polifonía aparece en las columnas de Burgos como una estrategia para romper la monotonía del texto, sorprender al lector y hacerlo sonreír.

Finalmente, hemos de destacar una última forma de interactuar con el lector, debido a la recurrencia del recurso y a las distintas posibilidades que presenta. Se trata del empleo de preguntas que el autor dirige a sus lectores o bien aquellas con las que recoge el punto de vista de estos.

Así pues, si dejamos al margen las preguntas que aparecen en diálogos ficticios o anecdóticos (“ ¿ $\mathrm{Y}$ a ti que te parece Doña Letizia?" ("Canutazos del Papa", 17/01/18)) y las que podemos calificar de expresiones hechas (“¿Quién dijo miedo? ("Gracias, director Nicolás Salas", 15/02/18)), hemos registrado el empleo de este recurso en 65 de las 88 columnas analizadas; esto es, en el 74\% de los textos periodísticos que conforman el corpus estudiado aparecen preguntas como mecanismo persuasivo en alguna de las dos vertientes siguientes:

\section{Preguntas del propio periodista}

A menudo aparece en las columnas preguntas o incluso una batería de ellas que, en cualquier caso, invitan a reflexionar al interlocutor:

(36) ¿Será que Iglesias, en su soberbia de eliminar a todo el que pueda hacerle sombra, ha echado de su cúpula de poder a gente como la señora Bescansa, la lactante, la que le daba el pecho a demanda a su bebé en el escaño del Congreso... mientras la carísima "salu" uniformada esperaba fuera para no descomponer la demagógica escena? (“Podemos, ¡que es de Huelva!", 2/02/18)

(37) Lo que no sé dirá, porque no interesa, es lo que me atrevo a preguntar. Con números, como los dorsales de marras:

1.- ¿Cuántos sevillanos y turistas perdieron ayer el avión por culpa del maratón?

2.- ¿Cuantos sevillanos y turistas perdieron el Ave por culpa del maratón? 
3.- ¿Cuántos viajeros del Ave que llegaron a Sevilla no pudieron ir a su destino final, a su casa o su hotel, porque todo estaba cortado con el maratón de los co...rredores?

4.- ¿Cuántos quedaron mal, por llegar tarde o no poder llegar a una cita por culpa del maratón?

Y las dos preguntas del millón, que también doy con números, como los dorsales. ("Maratón ni son”, 26/02/18)

Y en otras ocasiones formula preguntas que interpelan directamente al interlocutor:

(38) ¿Se imaginan la que se formaría en la incorporación a filas de cada reemplazo si los que entraran a servir a la Patria fuesen estos chavales de ahora, de botellona, píldora del día después y violencia escolar, los que denuncian a sus padres por maltrato, los que niegan toda autoridad y toda creencia, al tiempo que se ponen la camiseta de un Ernesto Guevara que, ché, ni saben quién fue? ("Crisis de autoridad", 15/01/18)

(39) ¿Saben que hay que hacer ante la ola de noticias falsas que nos invade? No creerse nada. De nadie ("Fakes", 4/02/18)

2. Preguntas que recogen el pensamiento del lector

(40) Esto ya está aquí. ¿Que qué está aquí? ¿Pues qué va a ser, miarma? ¡El primer nazareno, que ese sí que tira caramelos, y estampitas, y medallitas, y de tó! ("La trasera de la carroza de Baltasar", $6 / 01 / 18)$

(41) ¿Que quién ganó los Globos? Ah, eso es lo de menos. Como es de lo de menos saber quién gana los Goya ("Exportamos Goyas", $10 / 01 / 18)$

Traer la voz del propio receptor al discurso es una estrategia de gran valor persuasivo. Fuentes y Lara (2007: 20) afirman que se trata de un pretexto que pone en funcionamiento el juego argumentativo. En publicidad se utiliza muchísimo, de manera que la marca a menudo aparece "como alguien que acude a las necesidades de sus clientes, que refleja incluso sus estados de conciencia, y se hace portavoz de sus palabras". 
Burgos emplea este recurso polifónico de manera similar. Se hace eco de las reflexiones del receptor y las introduce en su discurso; con ello, consigue mostrar una imagen positiva no solo de este, sino de sí mismo, pues se presenta como alguien solidario con sus lectores, que les ofrece sus columnas para hacerse oír:

(42) - ¿ Y quién es la Real Academia para decir cómo hay que hacer las croquetas? ¿Es que los académicos de la Española se dedican a freír croquetas cuando se reúnen para incorporar nuevas palabras al Diccionario?

Eso digo yo. No fríen croquetas los académicos que se atreven a definirlas de un modo unívoco, cuando hay mil variantes ("Paul Bocuse no freía croquetas", 22/01/18)

Incluso lleva a cabo juegos basados en preguntas del periodista, a partir de las cuales surgen otras cuestiones dudosas que representan la réplica del lector y normalmente acaban con la respuesta de Burgos:

(43) Nadie cumple completa su pena, con tantos beneficios. ¿Por qué, si no quieren la prisión permanente, no exigir al menos el cumplimiento íntegro de las penas? ¿Que eso va contra la reinserción que dice la Constitución? ¿Pero dónde vamos a reinsertar a la presunta Ana Julia? Como no sea en la Familia Monster... (“Clamor no revisable”, 14/03/18)

En las dos vertientes analizadas el mecanismo de la modalidad interrogativa resulta una estrategia eficaz para cumplir con dos objetivos fundamentales del periodista: focalizar la atención del lector (rompen la monotonía del texto) y hacerlo partícipe del discurso.

\section{Consideraciones finales}

Pese a que la explotación sea diferente a la que se lleva a cabo en el habla real y espontánea, la imitación de los recursos orales 
en las columnas periodísticas es una práctica habitual en la actualidad, con la que el periodista consigue crear una cercanía y una complicidad con el lector para atraerlo hacia su punto de vista y persuadirlo, por tanto, de sus opiniones e interpretaciones.

Para lograr sus objetivos, el periodista tiene en consideración dos factores fundamentales tanto en la planificación de la columna como en su elaboración definitiva: por un lado, el deseo de mostrar su presencia continua en el discurso, manifestando su afectividad, y por otro, el de reflejar un cierto grado de interactividad.

Con respecto al segundo, en el estudio de la producción periodística de Antonio Burgos se ha observado el empleo de una serie de recursos particularmente fructuosos como estrategias discursivas de acercamiento a sus lectores.

Una de ellas es la alusión directa a un receptor concreto mediante el empleo de vocativos, ya sea para reprocharle algún asunto o, por el contrario, buscar su apoyo, y con ello reforzar la argumentación. En ambos casos se dirige a personalidades del panorama nacional o más asiduamente de las altas capas de la sociedad sevillana. La mayoría de los ejemplos analizados, como la de aquellos en que introduce en su narración el discurso directo para permitir hablar a los protagonistas de las anécdotas referidas, ponen de manifiesto su posición social y sus buenas relaciones en la ciudad hispalense. El estilo directo de estos personajes está cargado de rasgos de oralidad que aportan agilidad al relato, verosimilitud y mantienen la atención del receptor.

Asimismo, la presencia de marcadores conversacionales en el discurso dirigidos al receptor es otro recurso que refuerza la función de contacto con el interlocutor. En concreto, los marcadores epistémicos de evidencia (claro y naturalmente), así como el metadiscursivo sí y muy especialmente el enfocador de la alteridad vamos han sido los más empleados por el periodista.

Un aspecto interesante del análisis es la selección de los deícticos por parte de Burgos; consigue acortar la distancia espacio-temporal entre el momento de producción y el de recep- 
ción de sus columnas adoptando el punto de vista del lector, de manera que en sus narraciones, comentarios y recomendaciones las referencias temporales no suscitan ambigüedad alguna.

En cuanto a las fórmulas de tratamiento, utiliza la forma usted para dirigirse al lector; le muestra así todo su respeto y se pone de manifiesto que el deseo de crear lazos de complicidad no es incompatible con mantener una relación formal y de cortesía. Sin embargo, el lector, situado en una posición superior, sí tutea al periodista. Asimismo, el columnista selecciona la forma familiar tú para expresar opiniones o vivencias generales, en las que se incluyen ambos interlocutores.

Por último, hemos de destacar por su eficacia los recursos mediantes los cuales el propio lector participa en el discurso. El periodista no se limita a expresar las reacciones que les presupone, sino que crea todo un juego de comunicación polifónico a partir del cual el lector lo interrumpe para introducir un comentario, una reflexión o incluso para cuestionarlo y replicarle.

En ocasiones el lector se manifiesta a través de preguntas que, en cualquier caso, rompen la monotonía del texto y le otorgan un gran dinamismo. Asimismo, el humor constituye un componente fundamental en sus columnas; conocedor del impacto positivo que tiene en sus lectores, Burgos les dota de esa misma cualidad, de manera que a menudo sus intervenciones resultan más ocurrentes y lucidas que las del propio periodista.

La doble eficacia de estas estrategias de participación reside en que refuerzan la imagen de ambos interlocutores. Por un lado, se muestra al lector como un hablante hábil e ingenioso, y por otro, la imagen del propio Burgos resulta beneficiada, ya que aparece como alguien solidario y comprometido con sus lectores, a quienes les presta su vía de comunicación para que puedan expresar su punto de vista. Se afianza así la relación del periodista con sus receptores y con ello favorece su adhesión.

Por todo ello, las columnas periodísticas son un valioso material para su empleo en el proceso de enseñanza-aprendizaje del español coloquial actual. 


\section{Bibliografía}

Beinhauer, Werner (1963), El español coloquial, Madrid, Gredos.

Blanche-Benveniste, Claire (1998), Estudios lingüísticos sobre la relación entre oralidad y escritura, Barcelona, Gedisa.

Briz Gómez, ANTONio (1998), El español coloquial en la conversación. Esbozo de Pragmagramática, Barcelona, Ariel.

Bustos Tovar, José Jesús (1998), "El análisis de textos coloquiales”, en I. Carrasco y G. Fernández Ariza (eds.), El comentario de textos, Anejo XVII de Analecta Malacitana, Málaga, Universidad de Málaga, pp. 99-116.

Carbonero Cano, Pedro (1999), "Comentario sintáctico de un texto oral”, Analecta Malacitana, 3, pp. 211-221.

Casals Carro, María Jesús (2000), "La columna periodística: de esos embusteros días del ego inmarchitable”, en Estudios sobre el Mensaje Periodístico, 6, pp. 31-55, <https://revistas. ucm.es/index.php/ESMP/issue/view/ESMP000011> [consultado el 16 abril de 2018].

Charaudeau, P. y D. Maingueneau (2005), Diccionario de análisis del discurso, Buenos Aires, Amorrortu editores.

Coseriu, Eugenio (1981), Lecciones de lingüística general, Madrid, Gredos.

DeMello, George (2000), “'Tú' impersonal en el habla culta”, Nueva Revista de Filología Hispánica, XLVIII, 2, pp. 359-372, <https://nrfh.colmex.mx/index.php/nrfh/issue/ view/130> [consultado el 7 mayo de 2018].

Fernández Ramírez, SAlvador (1986), Gramática española 4. El verbo y la oración, Madrid, Arco/Libros.

Fuentes Rodríguez, CATAlina (2000), Lingüística pragmática y análisis del discurso, Madrid, Arco/Libros.

Fuentes Rodríguez, Catalina y Esperanza Alcaide Lara (2002), Mecanismos lingüísticos de la persuasión, Madrid, Arco/Libros.

Fuentes Rodríguez, Catalina y Esperanza Alcaide Lara (2007), La argumentación lingüística y sus medios de expresión, Madrid, Arco/Libros. 
Haverkate, Henk (1994), La cortesía verbal. Estudio pragmalingüístico, Madrid, Gredos.

Kluge, Bettina (2010), "El uso de formas de tratamiento en las estrategias de generalización”, en M. Hummel, B. Kluge y M. E. Vázquez Laslop (eds.), Formas y fórmulas de tratamiento en el mundo hispánico, México, El Colegio de México / Karl-Franzens-Universität Graz, pp. 1109-1136.

Koch, Peter y Wulf Oesterreicher (1985), "Sprache der Nähe - Sprache der Distanz. Mündlichkeit und Schriftlichkeit im Spannungsfeld von Sprachtheorie und Sprachgeschichte", Romanistisches Jahrbuch, 36, pp. 15-43.

León-Castro, Marta (2014), "Sobre el empleo de la segunda persona del singular como mecanismo de indefinición referencial en el habla culta. Diferencias entre las formas tú/ vos y usted", Lingüística y Literatura, 65, pp. 37-63, <http:// aprendeenlinea.udea.edu.co/revistas/index.php/lyl/ article/view/18835>.

León-Castro, Marta (2015), "Variación de la segunda persona del singular como estrategia de indeterminación referencial en el habla de Sevilla: sociolecto alto", en J. Santana Marrero (dir.), M. León-Castro Gómez y A. Zerva (coords.), La variación en el español actual: estudios dedicados al profesor Pedro Carbonero, Sevilla, Universidad de Sevilla, pp. 211-232.

Mancera Rueda, Ana (2008), "Oralidad y coloquialidad en la prensa española: la columna periodística”, en I. Olza Moreno, M. Casado Velarde y R. González Ruiz (eds.), Actas del XXXVII Simposio Internacional de la Sociedad Española de Lingüística (SEL), Pamplona, Universidad de Pamplona, pp. 469-478.

Mancera Rueda, Ana (2009), 'Oralización' de la prensa española: la columna periodística, Berna, Peter Lang.

Martín Zorraquino, María Antonia y José Portolés LÁzaro (1999), "Los marcadores del discurso", en I. Bosque y V. Demonte (dirs.), Gramática descriptiva de la lengua española, vol. 3, pp. 4051-4214.

Menéndez, S. M. (2000), "Estrategias discursivas: principio metodológico para el análisis pragmático del discurso", en 
J. J. Bustos Tovar (coord.), Lengua, discurso, texto (I Simposio Internacional de Análisis del Discurso), vol. I, Madrid, Universidad Complutense de Madrid / Visor, pp. 923-946. NARbona Jiménez, Antonio (1989), Sintaxis española: nuevos y viejos enfoques, Barcelona, Ariel.

Narbona Jiménez, Antonio (1994), "Hacia una sintaxis del español coloquial”, en Actas del Congreso de la Lengua Española, Madrid, Instituto Cervantes, pp. 721-740.

Porroche Ballesteros, Margarita (2012), "Oralidad y escritura en las columnas de opinión de la prensa zaragozana actual", Archivo de Filología Aragonesa, 68, pp. 231-252, <https://ifc.dpz.es/recursos/ publicaciones/32/82/11porroche.pdf> [consultado el 29 marzo de 2018].

Real Academia Española (2014), Diccionario de la lengua española, <http://dle.rae.es/?w=diccionario $>$ [consultado el 12 abril de 2018].

Real Academia Española y Asociación de Academias de la Lengua Española (2009), Nueva gramática de la lengua española, Madrid, Espasa.

Vigara Tauste, Ana María (2000), "Sobre deixis coloquial", Círculo de Lingüística Aplicada a la Comunicación, 1, pp. 95-117, <http://webs.ucm.es/info/circulo/no1/vigara. htm $>$ [consultado el 3 abril de 2018].

\section{$\sim$ \\ Marta León-Castro}

Doctora en Filología Hispánica y Licenciada en Periodismo (ambos títulos por la Universidad de Sevilla). En la actualidad es profesora del Departamento de Lengua Española, Lingüística y Teoría de la Literatura e imparte diversas asignaturas del área de Lengua Española en los grados de Filología Hispánica, Publicidad y Relaciones Públicas, Periodismo y Comunicación Audiovisual, así como en el Máster Universitario en Profesorado de Educación Secundaria y Bachillerato, FP y Enseñanzas de Idiomas (MAES). Es miembro del grupo de In- 
vestigación Sociolingüística Andaluza: Estudio Sociolingüístico del Habla de Sevilla HUM-141), del Proyecto de Estudio Sociolingüístico del Español de España y América (PRESEEA-SE) y del Proyecto Patrones Sociolingüísticos del Español de Sevilla (PASOS-SE) (REF.ff1201568171-C, MINECO/ FEDER, UE), marco en el que desarrolla sus investigaciones sobre atenuación, especialmente centrados en el estudio de los mecanismos impersonalizadores que ha publicado en diversas revistas de reconocido prestigio. 